\title{
Investigation on the Inversion of the Atmospheric Duct Using the Artificial Bee Colony Algorithm Based on Opposition-Based Learning
}

\author{
Chao Yang, ${ }^{1}$ Jian-Ke Zhang, ${ }^{1}$ and Li-Xin Guo ${ }^{2}$ \\ ${ }^{1}$ School of Science, Xian University of Posts and Telecommunications, Xian 710121, China \\ ${ }^{2}$ School of Physics and Optoelectronic Engineering, Xidian University, Xi'an 710071, China \\ Correspondence should be addressed to Chao Yang; yang_chaomail@163.com
}

Received 14 January 2016; Accepted 21 March 2016

Academic Editor: Sotirios K. Goudos

Copyright (C) 2016 Chao Yang et al. This is an open access article distributed under the Creative Commons Attribution License, which permits unrestricted use, distribution, and reproduction in any medium, provided the original work is properly cited.

\begin{abstract}
The artificial bee colony $(\mathrm{ABC})$ algorithm is a recently introduced optimization method in the research field of swarm intelligence. This paper presents an improved $\mathrm{ABC}$ algorithm named as OGABC based on opposition-based learning (OBL) and global best search equation to overcome the shortcomings of the slow convergence rate and sinking into local optima in the process of inversion of atmospheric duct. Taking the inversion of the surface duct using refractivity from clutter (RFC) technique as an example to validate the performance of the proposed OGABC, the inversion results are compared with those of the modified invasive weed optimization (MIWO) and ABC. The radar sea clutter power calculated by parabolic equation method using the simulated and measured refractivity profile is utilized to carry out the inversion of the surface duct, respectively. The comparative investigation results indicate that the performance of OGABC is superior to that of MIWO and $\mathrm{ABC}$ in terms of stability, accuracy, and convergence rate during the process of inversion.
\end{abstract}

\section{Introduction}

The lower atmospheric duct commonly encountered in marine boundary layer is an abnormal electromagnetic environment due to the sharp variations of atmospheric temperature and humidity above the sea surface. In the ducting environment, the performance of radar system and communication system can be significantly changed, such as the maximum operation range, creation of radar holes where the radar is practically blind, and strengthened sea surface clutter $[1,2]$. Therefore, it is of great importance to infer the atmospheric duct owing to its considerable effect on the radar and communication system that are designed to work under standard atmospheric conditions with a typical slope of $0.118 \mathrm{M}$-units/s [3].

In general, the atmospheric duct is represented by the modified refractivity profile. The traditional methods of determining the atmospheric duct include radiosondes, rocketsondes, microwave refractometers, and lidar. Nevertheless, the traditional measurement methods have the drawbacks of high cost and containing many restrictive factors. Recently, RFC technique $[4,5]$ has been a promising method to infer the atmospheric duct. It uses the propagation characteristics of radar sea clutter signal to infer the modified refractivity profile information of atmospheric duct. And the RFC technique has the advantages of simple devices and easy implementation.

Inversion of atmosphere duct from the RFC technique has been an important research subject over the past several decades owing to its important applications in radar system and communication system. More attention is paid to the study of inversion model and optimization model in RFC technique. The detailed procedures of RFC technique are given by Gerstoft et al. [4], and the inversion of the range dependent and independent atmospheric duct using RFC technique is implemented by genetic algorithm. Karimian et al. [5] published a review paper on the latest research developments and the direction of future work to be done 
about RFC technique. Zhao et al. $[6,7]$ derive the inversion theoretical framework of adjoint method from parabolic equation model, and the feasibility of the adjoint method is validated by numerical simulations. As is known to all, estimation of atmosphere duct using RFC technique is an inverse problem. Taking the nonlinear relation between the forward propagation model and atmospheric duct parameters into consideration, the investigation on the optimization models with high performance is one of the most important research topics in the field of inversion of the atmospheric duct from radar sea clutter. For instance, the least square support vector machine, the particle swarm optimization (PSO), the simulated annealing algorithm, and the ABC algorithm have been applied to infer the atmospheric duct using RFC technique [8-11].

The ABC algorithm [12] is one of the most recently proposed swarm intelligence algorithms which simulates the intelligent behavior of honeybee swarm. In ABC, the optimization procedures are implemented by simulating the intelligent foraging behavior of a honeybee swarm to share information of bees for the purpose of finding the optimal solution. Currently, the $\mathrm{ABC}$ algorithm has been applied to the design of antenna and electromagnetic devices [13-15]. In addition, the $\mathrm{ABC}$ algorithm has been used to infer the atmospheric duct from RFC technique [11], and the comparative study results demonstrate that the performance of $\mathrm{ABC}$ is superior to that of the PSO for the inversion of atmospheric duct. However, the $\mathrm{ABC}$ also has the drawbacks of easily falling into local optima and slower convergence rate. To overcome this issue, the improved $\mathrm{ABC}$ has been proposed by updating the search equation to enhance its optimization performance, and the improved $\mathrm{ABC}$ is validated by benchmark function $[16,17]$. In recent years, the OBL was introduced by Rahnamayan et al. [18] and has been proven to be a useful strategy to enhance the accuracy and convergence rate of the optimization algorithm, such as differential evolution and PSO.

In this paper, the $\mathrm{OGABC}$ is proposed by incorporating the $\mathrm{OBL}$ strategy and global best search equation into the $\mathrm{ABC}$ to enhance the performance of $\mathrm{ABC}$ in the inversion of atmospheric duct. In OGABC, the OBL is used to accelerate the convergence rate, and the global best search equation is adopted to balance the local and global search ability.

\section{The Propagation Model and Objective Function}

2.1. Parabolic Equation Method. Considering that the parabolic equation method has the advantages of high stability and accuracy, it has been extensively utilized to investigate the tropospheric electromagnetic wave propagation. In rectangular coordinates, the parabolic equation can be represented as

$$
\frac{\partial^{2} u}{\partial z^{2}}+2 i k_{0} \frac{\partial u}{\partial x}+k_{0}^{2}\left(n^{2}-1\right) u=0
$$

where $n$ is the refractive index and $k_{0}$ is the free space wave number.
If the initial field is provided, the split step Fourier solution of parabolic equation method at different range can be easily obtained by [19]

$$
\begin{aligned}
& u\left(x_{0}+\Delta x, z\right) \\
& \quad=e^{\left(i k_{0} / 2\right)\left[n^{2}-1\right] \Delta x} F^{-1}\left\{e^{\left(i \Delta x / 2 k_{0}\right) p^{2}} F\left[u\left(x_{0}, z\right)\right]\right\},
\end{aligned}
$$

where $F$ and $F^{-1}$ are the Fourier transform and inverse Fourier transform, respectively, $p$ is the transform variable, $\Delta x$ is the distance interval, and $u\left(x_{0}, z\right)$ is the initial field. It should be pointed out that this research mainly focuses on the inversion of atmospheric duct; more detailed information on the propagation problem with parabolic equation method can be found in [19].

2.2. Radar Sea Clutter Power. In RFC technique, the objective function is described by the radar sea clutter power at different propagation distances. Taking the influence of atmosphere condition into account, the received radar sea clutter power based on radar equation can be expressed in $\mathrm{dB}$ by [4]

$$
P_{c}(\mathbf{m})=-2 L+\sigma^{\circ}+10 \lg (r)+C,
$$

where $L$ is the propagation loss calculated by the parabolic equation method, $\sigma^{\circ}$ is the radar cross section obtained by the GIT sea clutter model [20], $r$ is the propagation distance, $C$ is a constant that includes wavelength, transmitter power, and antenna gain, and $\mathbf{m}$ is the parameter vector of the atmospheric duct.

In this paper, the surface based duct is described by the following four-parameter model [2]:

$$
\begin{aligned}
& M(z)=M_{0} \\
& \quad+ \begin{cases}c_{1} z & z<h_{1} \\
c_{1} h_{1}+c_{2}\left(z-h_{1}\right) & h_{1} \leq z \leq h_{2} \\
c_{1} h_{1}+c_{2} h_{2}+0.118\left(z-h_{1}-h_{2}\right) & z>h_{2},\end{cases}
\end{aligned}
$$

where $M_{0}$ is the base refractivity and $c_{1}$ and $h_{1}$ stand for the slope and thickness of the base layer, whereas $c_{2}$ and $h_{2}$ represent the slope and thickness of the inversion layer, respectively.

2.3. The Objective Function. In the process of inversion, the commonly used least squares objective function is given by [4]

$$
\begin{aligned}
f(\mathbf{m}) & =\mathbf{e}^{\mathrm{T}} \mathbf{e}, \\
\mathbf{e} & =\mathbf{P}_{c}^{\mathrm{obs}}-\mathbf{P}_{c}(\mathbf{m})-\widehat{T}, \\
\widehat{T} & =\overline{\mathbf{P}}_{c}^{\mathrm{obs}}-\overline{\mathbf{P}}_{c}(\mathbf{m}),
\end{aligned}
$$

where $\mathbf{P}_{c}^{\text {obs }}$ and $\mathbf{P}_{c}(\mathbf{m})$ stand for the observed and received sea clutter power at different ranges and $\overline{\mathbf{P}}_{c}^{\text {obs }}$ and $\overline{\mathbf{P}}_{c}(\mathbf{m})$ denote the average power of $\mathbf{P}_{c}^{\text {obs }}$ and $\mathbf{P}_{c}(\mathbf{m})$, respectively. 


\section{The Proposed OGABC Algorithm}

3.1. The OBL. The OBL strategy can improve the convergence rate and accuracy of optimization algorithm by simultaneously evaluating the initial solution and opposite solution for the population initialization and for the generation jumping. The probability theory indicates that the opposite solution can increase the opportunity of approaching the global best solution in the search process. The definitions of opposite number and opposite solution are given by [18].

Definition 1. Let $x \in[l, u]$ be a real number. Its corresponding opposite number $\tilde{x}$ is defined by

$$
\tilde{x}=l+u-x .
$$

Definition 2. Let $X=\left(x_{1}, x_{2}, \ldots, x_{D}\right)$ be a solution in $D$ dimensional space, where $x_{i} \in\left[l_{i}, u_{i}\right]$ and $l_{i}, u_{i}$ are lower and upper bounds of the $i$ th dimension. The corresponding opposite solution $\widetilde{X}=\left(\widetilde{x}_{1}, \widetilde{x}_{2}, \ldots, \widetilde{x}_{D}\right)$ is defined by

$$
\tilde{x}_{i}=l_{i}+u_{i}-x_{i} \quad i=1, \ldots, D .
$$

In this paper, the inversion of atmospheric duct is a minimization problem. With the help of the definition of opposite solution, the OBL in the inversion of atmospheric duct can be described by the following: if $f(\widetilde{X}) \leq f(X)$, then random solution $X$ can be replaced with $\widetilde{X}$; otherwise, we continue with $X$. Additionally, according to a jumping rate, the better population for the next iteration can be obtained by the generation jumping using the current and their corresponding opposite population. Evidently, the random solution and opposite solution are simultaneously evaluated to select the better solution in the search process.

3.2. The Proposed $O G A B C$ and Its Implementation Steps. The $\mathrm{ABC}$ is one of the most recent swarm intelligence optimization algorithms proposed by Karaboga under the inspiration of the intelligent foraging behavior of honeybee swarm. In $A B C$, there are three types of honeybees: employed bees, onlooker bees, and scouts. The position of a food source stands for a possible solution of the optimization problem and the nectar amount of a food source is employed to evaluate the quality of the solution. The number of employed bees is equal to the number of food sources and the half of the population size. The employed bees undertake the responsibility of searching for food sources and share the effective information with onlooker bees. The onlooker bees try to make a further selection of the excellent food sources based on the information provided by employed bees. If the quality of food source cannot be improved through a predetermined condition, the corresponding food source becomes a scout. Then, the scout begins to randomly generate a new food source at the neighborhood of the hive.

In order to enhance the performance of $A B C$ in the inversion of atmospheric duct, the OGABC is presented by incorporating the OBL strategy and global best search equation into $\mathrm{ABC}$ algorithm. The main steps of OGABC are summarized as follows.
Step 1 (opposition-based population initialization). Step 1 contains the following.

Step 1.1. Randomly produce $D$-dimensional population $X_{0}$ of $N$ solutions by

$$
\begin{aligned}
X_{0 i, j}=l_{j}+\operatorname{rand}(0,1) & \left(u_{j}-l_{j}\right) \\
& i=1,2, \ldots, N ; j=1,2, \ldots, D .
\end{aligned}
$$

Step 1.2. Generate the opposite population $O X_{0}$ of $X_{0}$ by

$$
O X_{0 i, j}=l_{j}+u_{j}-X_{0 i, j} \text {. }
$$

Step 1.3. Choose the $N$ best solutions from $\left[X_{0} ; O X_{0}\right]$ according to the fitness value to produce the initial population.

Step 2 (in employed bees stage). Step 2 contains the following.

Step 2.1. Update the position of food sources using the global best search (10) [16] and evaluate the quality of the new position of food sources:

$$
\begin{array}{r}
v_{i j}=x_{i j}+\phi_{i j}\left(x_{i j}-x_{k j}\right)+\psi_{i j}\left(y_{j}-x_{i j}\right) \\
(i, k=1, \ldots, N, j=1, \ldots, D),
\end{array}
$$

where the subscripts $k, i$, and $j$ are randomly selected and satisfy $k \neq i, y_{j}$ is the $j$ th element of the global best solution, and $\phi_{i j}$ and $\psi_{i j}$ are uniform random number in $[-1,1]$ and $[0,1.5]$, respectively.

Step 2.2. Apply the greedy selection mechanism to choose the better food source between the old and new food source.

Step 3. Calculate the probability of each food source according to

$$
p_{i}=\frac{\text { fit }_{i}}{\sum_{k=1}^{N} \mathrm{fit}_{k}},
$$

where fit ${ }_{i}$ represents the fitness value of the food source $i$ computed in employed bees stage.

Step 4 (in onlooker bees stage). Step 4 contains the following.

Step 4.1. Update the position of food sources using (10) according to the probability computed in Step 3 .

Step 4.2. Apply the greedy selection mechanism again to choose the better food source.

Step 5. Memorize the best solution so far.

Step 6. In scouts stage, decide whether a food source becomes a scout or not; if it exists, the food source is replaced by a new random solution.

Step 7 (opposition-based generation jumping). Step 7 contains the following. 


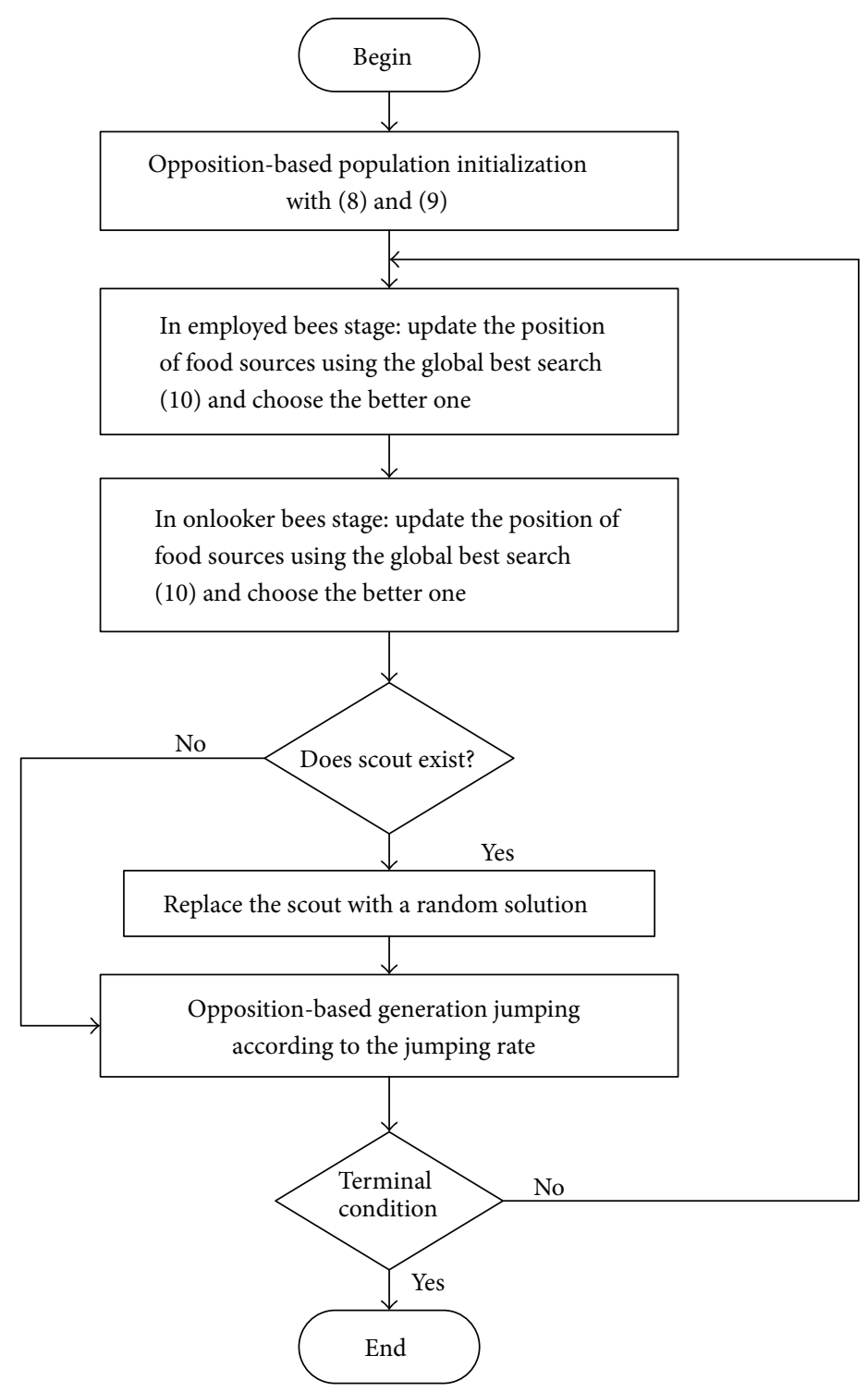

FIgURE 1: The flowchart of the proposed OGABC algorithm.

Step 7.1. According to the jumping rate, decide whether opposition-based generation jumping appears or not; if it appears, the new opposite population $O X$ of $X$ are produced by

$$
\begin{aligned}
O X_{i, j}=l_{j}^{\min }+u_{j}^{\max }- & X_{i, j} \\
& \quad i=1,2, \ldots, N ; j=1,2, \ldots, D,
\end{aligned}
$$

where $l_{j}^{\min }$ and $u_{j}^{\max }$ are the minimum and maximum value of the $j$ th dimension in the current population.

Step 7.2. Choose the $N$ best solutions from $[X ; O X]$ according to the fitness value to generate the population for the next iteration.
Step 8. Repeat Step 2 to Step 7 until a terminating condition is met.

The flowchart of the proposed OGABC is shown in Figure 1.

\section{The Numerical Results and Discussions}

In this section, the inversion results are given to validate the optimization performance of the proposed OGABC. In the following, we take the inversion of the four-parameter surface duct with RFC technique as an example to analyze the performance of $\mathrm{OGABC}$ and the inversion results are compared with those of the MIWO [21] and ABC.

In fact, the essence of the inversion of surface duct is to obtain its corresponding refractivity profile determined 

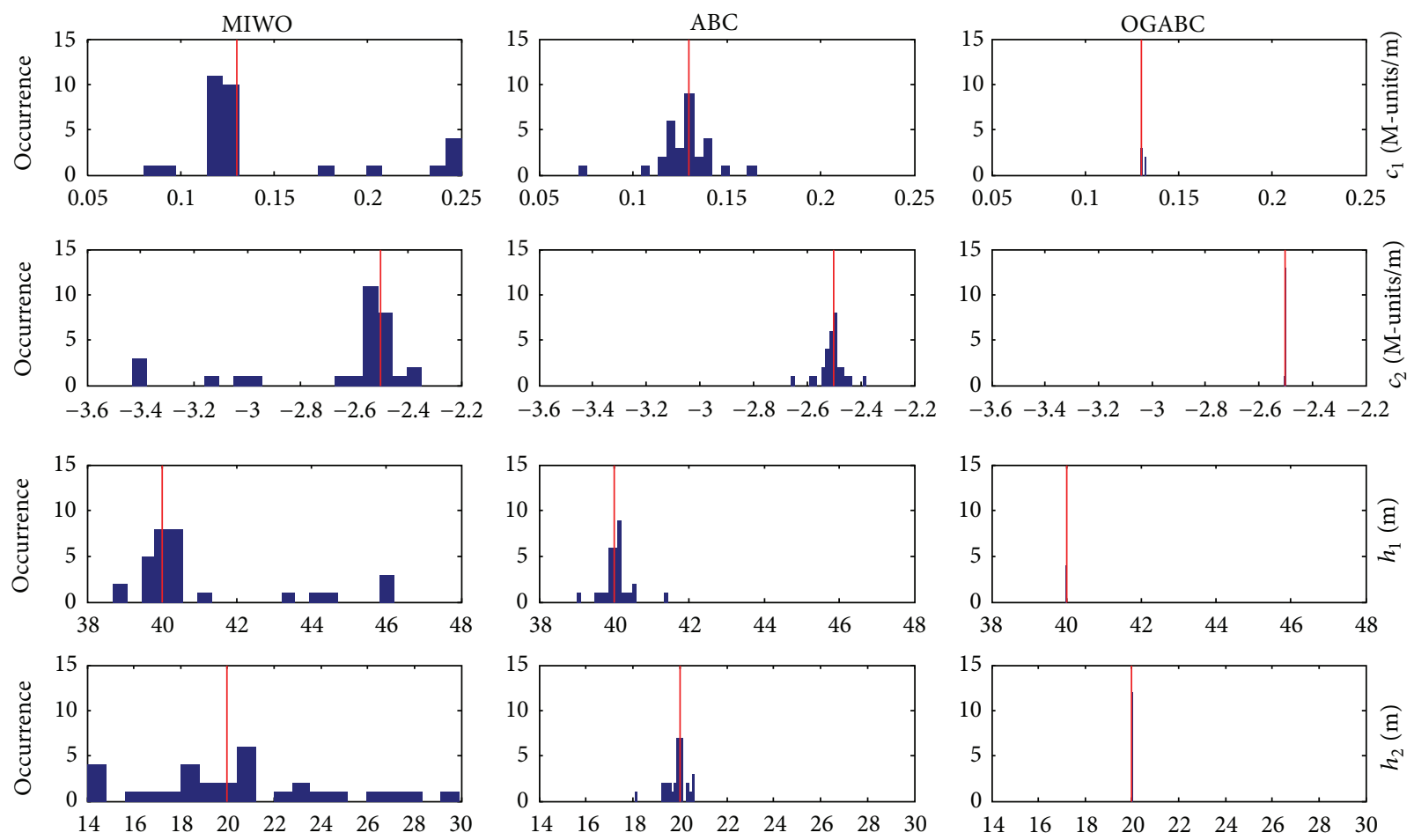

FIgURE 2: The comparison of the histograms of the inversion results for different algorithms with the noise level of $0 \mathrm{~dB}$.

TABLE 1: The lower and upper search bounds of the parameters.

\begin{tabular}{lccc}
\hline Parameter & Lower bound & Upper bound & Units \\
\hline$c_{1}$ & 0.0 & 0.25 & M-units $/ \mathrm{m}$ \\
$c_{2}$ & -3.5 & -1.0 & M-units $/ \mathrm{m}$ \\
$h_{1}$ & 25.0 & 50.0 & $\mathrm{~m}$ \\
$h_{2}$ & 10.0 & 30.0 & $\mathrm{~m}$ \\
\hline
\end{tabular}

by (4). In other words, the optimization problem can be translated into the inversion of the parameters of the surface duct $\mathbf{m}=\left(c_{1}, c_{2}, h_{1}, h_{2}\right)$, and the lower and upper bounds of the surface duct parameters are shown in Table 1.

In numerical simulation, the inversions are implemented by the radar sea clutter power calculated by parabolic equation method using the simulated and measured refractivity profile, respectively. During the inversion, the simulated radar sea clutter power from $10 \mathrm{Km}$ to $50 \mathrm{Km}$ is regarded as the observed radar sea clutter power, and the radar system operates at a frequency of $10 \mathrm{GHz}$, power of $91.4 \mathrm{dBm}$, antenna gain of $52.8 \mathrm{~dB}$, antenna height of $7 \mathrm{~m}$, beam width of $0.7^{\circ}, 600 \mathrm{~m}$ range bin, and $\mathrm{HH}$ polarization. In addition, the control parameters of OGABC are given as follows: the population size is 60 , the number of food sources is 30 , the parameter limit is 25 , the maximum number of iterations is 120 , and the jumping rate of OBL is 0.3 [18]; the parameters settings for MIWO are given as follows: the initial population size is 30 , the maximum population size is
40 , the maximum number of iterations is 120 , the nonlinear modulation index is 3 , the minimum and maximum numbers of seeds are 0 and 10, the initial and final value of standard deviation are 10.0 and 0.0001 , and the inversion results are obtained from 30 independent runs for each algorithm for the simulated refractivity profile case. For a fair comparison between $\mathrm{ABC}$ and $\mathrm{OGABC}$, they are examined using the same parameter settings, and the settings of the radar system remain unchanged in the process of inversions.

For the simulated refractivity case, the radar sea clutter power computed by the parameters of the surface duct $\mathbf{m}=$ $(0.13,-2.5,40,20)$ is utilized to the inversion of the surface duct. Moreover, the Gaussian noise with zero mean and different standard deviations is added to the simulated radar sea clutter power to examine the stability of the algorithms, and the standard deviation is employed to represent the noise level. Also, the histograms and convergence curves are presented to analyze the accuracy and convergence rate in detail.

Figures 2-5 give the comparison of the histograms of the inversions of the surface duct parameters for different algorithms at a specific noise level, and the red lines denote the actual parameter of surface duct. It is obvious that the distribution of inversion parameters obtained by the OGABC is more intensive than those of MIWO and $\mathrm{ABC}$ for different noise level. In addition, the inversion results of OGABC achieve the most occurrence at the vicinity of the actual parameter compared with those of the MIWO and ABC. That is to say, the proposed OGABC is the most stable algorithm 

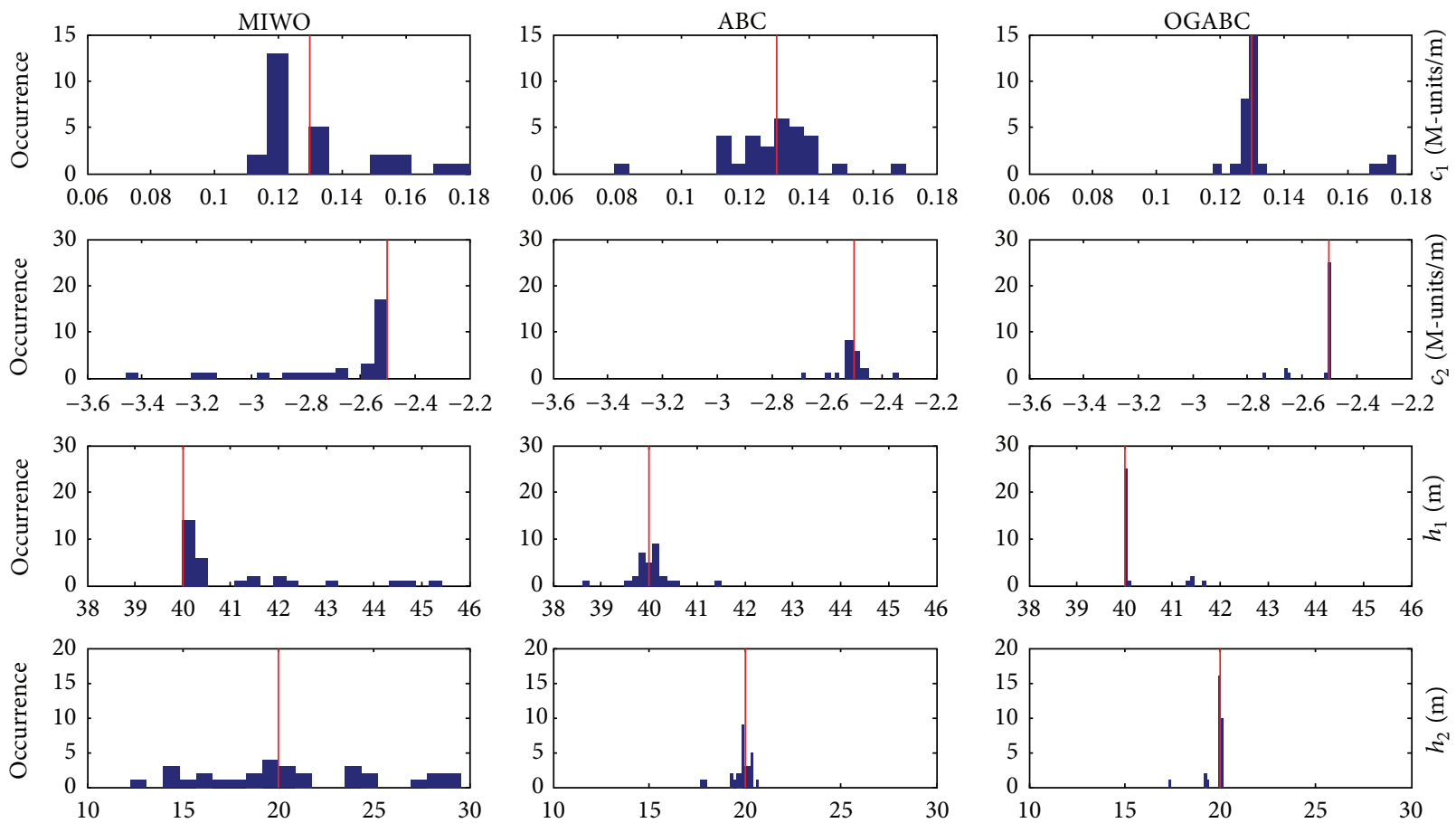

FIGURE 3: The comparison of the histograms of the inversion results for different algorithms with the noise level of $1 \mathrm{~dB}$.
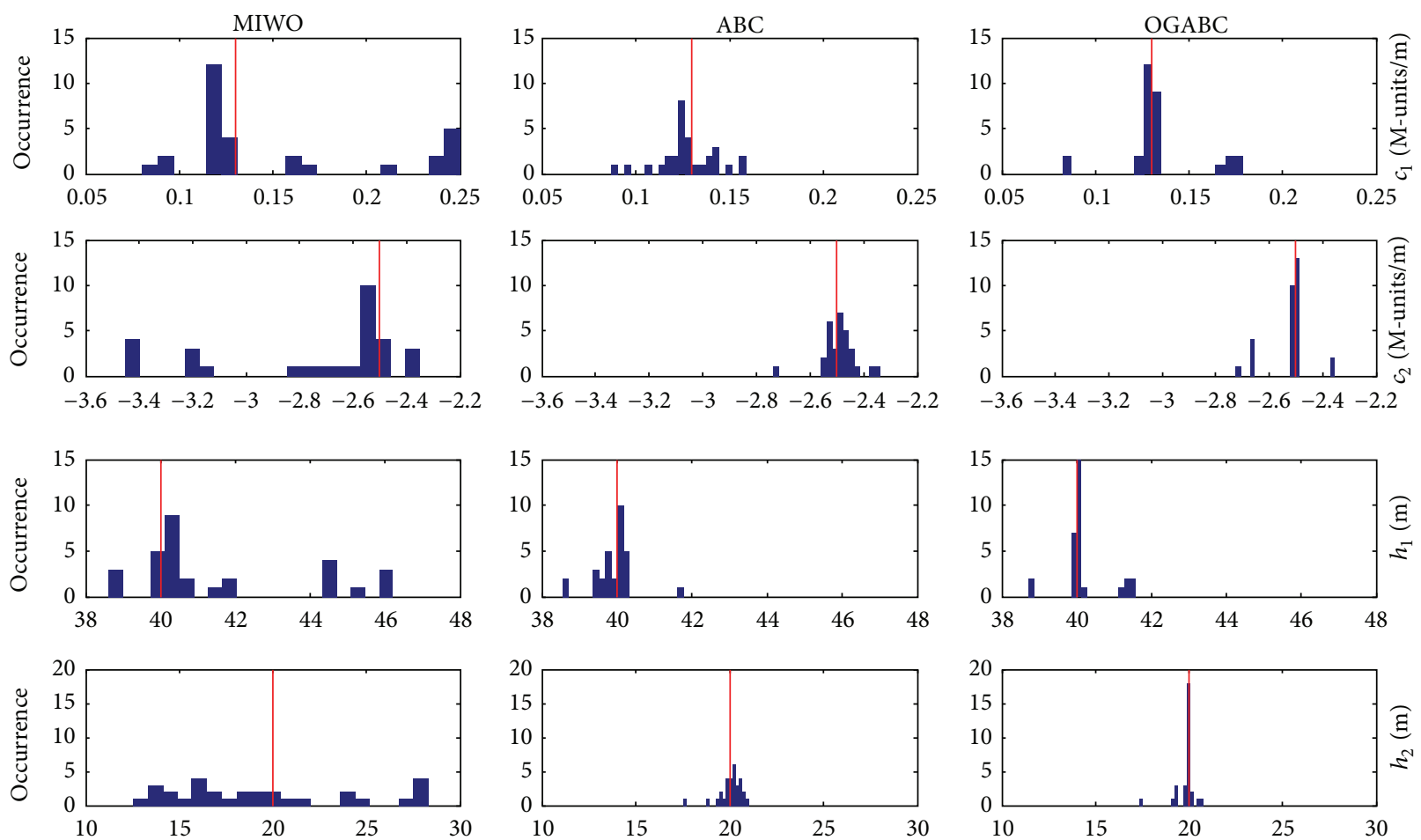

FIGURE 4: The comparison of the histograms of the inversion results for different algorithms with the noise level of $2 \mathrm{~dB}$.

among the three algorithms. It is likely due to the fact that the global best search equation not only enhances the global search ability but also avoids falling into the local minimum.

To study the convergence performance of the OGABC, the comparisons of the convergence curves of different algorithms based on the inversion results given in Figures 2-5 with the same noise level are demonstrated in Figure 6. It can be seen that the convergence rate of $\mathrm{OGABC}$ is faster than that of the MIWO and ABC; besides, the OGABC has the smallest mean minimum fitness at the end of the iteration for 

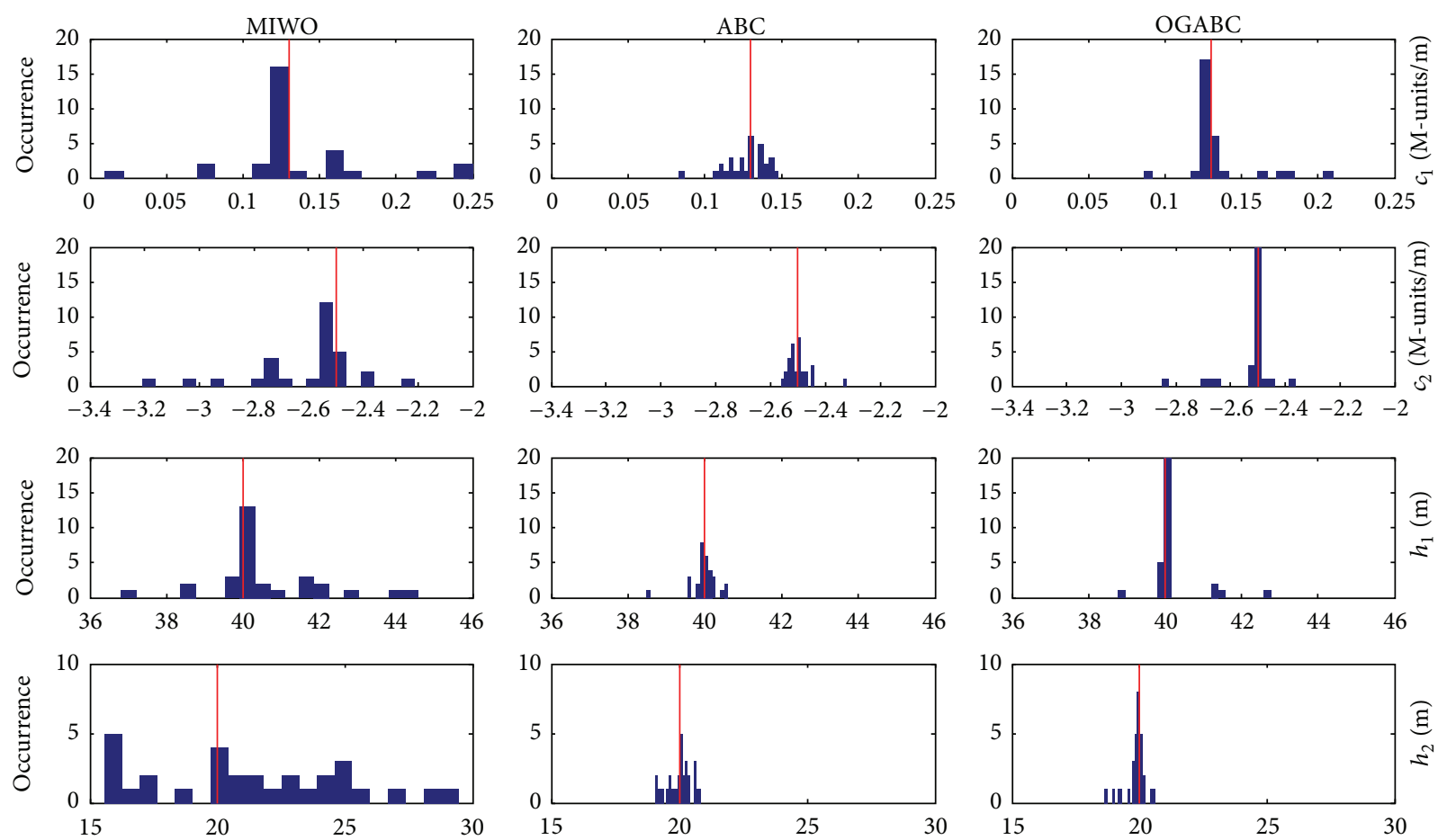

FIgURE 5: The comparison of the histograms of the inversion results for different algorithms with the noise level of $3 \mathrm{~dB}$.

different noise level. The convergence curves indicate that the $\mathrm{OGABC}$ is the best algorithm among the three algorithms. This can be attributed to the fact that the OBL can produce a relatively excellent initial population in the initialization stage and a generation jumping to form a better population in the search process.

The accuracy of the inversion of atmospheric duct is of crucial importance to exactly predict the marine electromagnetic environment. Hence, the comparisons of the difference between the inverted and actual radar coverage diagram simulated by parabolic equation method for different noise level are shown in Figure 7, and the peaks of the parameter distributions [20] in Figures 2-5 are treated as the inverted parameters of the surface duct to simulate their corresponding coverage diagram. Nevertheless, it is hardly possible to evaluate the quality of the algorithms according to the results presented in Figure 7. Thus, a new quantitative evaluation criterion named Mean Absolute Error (MAE) is given by

$$
\text { MAE }=\frac{\sum_{i=1}^{N_{x}} \sum_{j=1}^{N_{y}}\left|\mathrm{PL}_{i}(i, j)-\mathrm{PL}_{a}(i, j)\right|}{N_{x} N_{y}},
$$

where $\mathrm{PL}_{i}(i, j)$ and $\mathrm{PL}_{a}(i, j)$ represent the inverted and actual propagation loss calculated at discrete point $(i \Delta x, j \Delta y)$ and $N_{x}$ and $N_{y}$ are the sample points along the horizontal and vertical direction, respectively. It is easy to see that the smaller the MAE, the higher the accuracy of the algorithm.

The MAE of the three algorithms for different noise level obtained by (13) are presented in Table 2, and the minimum
TABLE 2: The comparison of the MAE for different algorithms with different noise level.

\begin{tabular}{lccc}
\hline Noise level & MIWO & $\begin{array}{c}\text { Algorithms } \\
\text { ABC }\end{array}$ & OGABC \\
\hline $0 \mathrm{~dB}$ & 2.22 & 1.64 & $\mathbf{0 . 0 9}$ \\
$1 \mathrm{~dB}$ & 1.88 & 0.88 & $\mathbf{0 . 7 5}$ \\
$2 \mathrm{~dB}$ & 3.54 & 1.84 & $\mathbf{1 . 0 5}$ \\
$3 \mathrm{~dB}$ & 3.25 & 0.79 & $\mathbf{0 . 6 0}$ \\
\hline
\end{tabular}

results are highlighted in bold. It can be observed from Table 2 that the MAE of OGABC is the smallest one among the three algorithms for different noise level; namely, the accuracy of OGABC is superior to MIWO and ABC.

Then, in order to further test the performance of OGABC, the radar sea clutter power generated by measured refractivity profile [20] is also utilized for the inversion of the surface duct. Figure 8 shows the comparison of the inverted profile obtained by the three algorithms with the measured profile, and it is distinct that the inverted profile of OGABC is in excellent agreement with the measured one.

In addition, Figure 9 presents the corresponding comparison of the convergence curves of the MIWO, ABC, and OGABC. It is observed that the three algorithms have the faster convergence rate at the early stage of iterations, and the minimum fitness is hardly changed with iteration at the middle and later stage of iterations. However, the OGABC has the smallest minimum fitness among the three algorithms. 


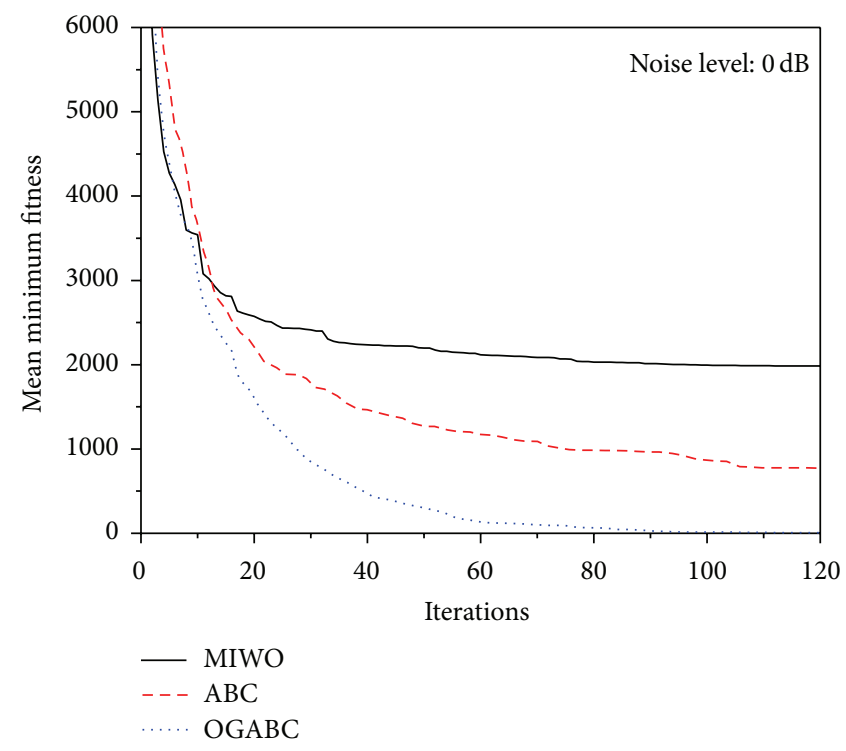

(a)

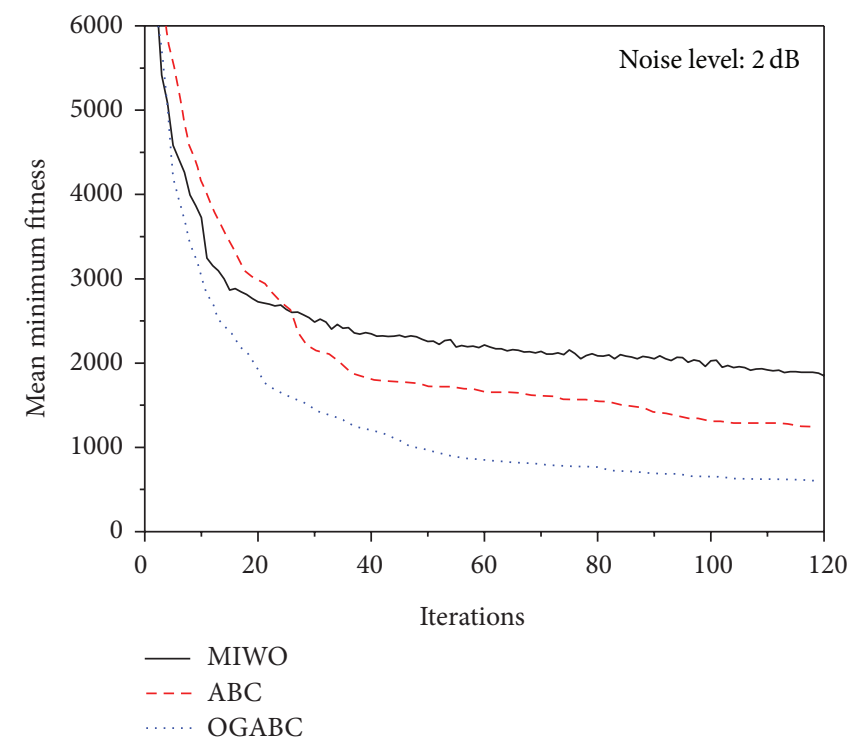

(c)

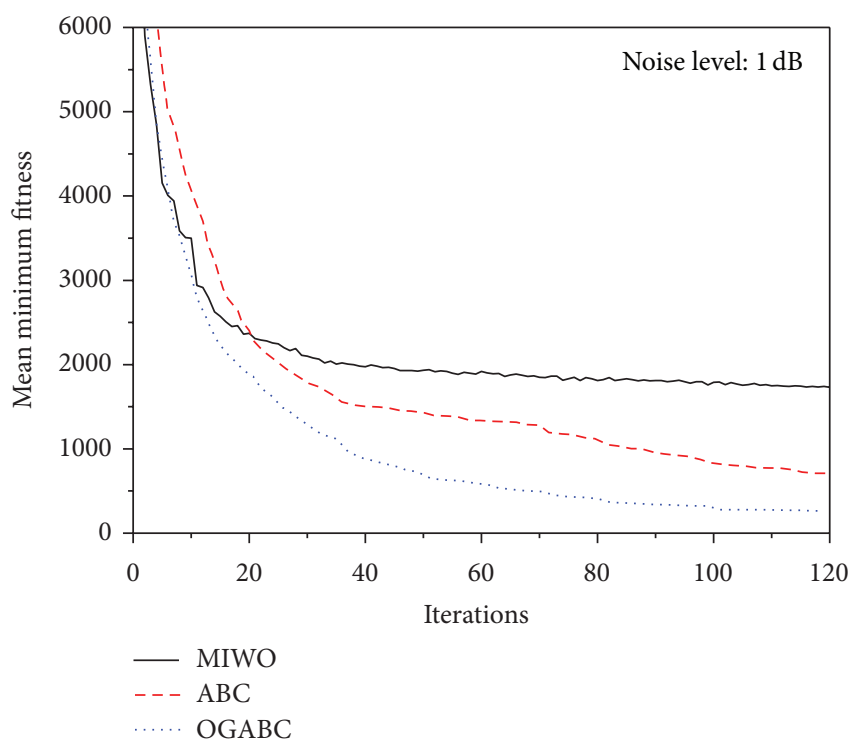

(b)

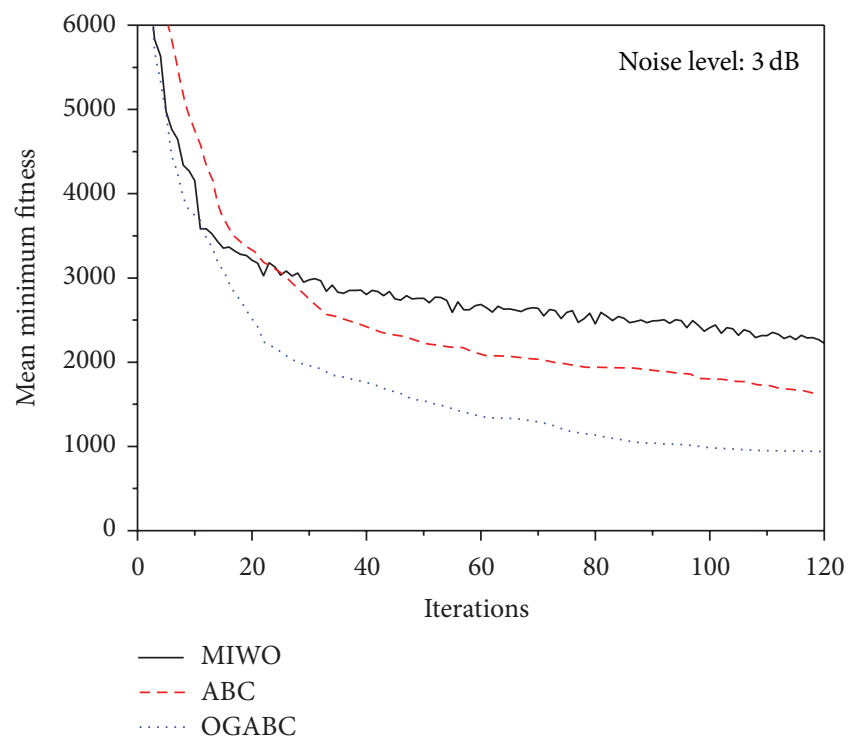

(d)

FIgURE 6: The comparison of the convergence curves of different algorithms with the same noise level.

That is to say, the OGABC is superior to MIWO and ABC according to the accuracy and convergence rate.

\section{Conclusion}

In this paper, an improved $\mathrm{ABC}$ algorithm called $\mathrm{OGABC}$ is presented by simultaneously merging the OBL strategy and global best search equation into the standard $A B C$ algorithm to tackle its deficiency of slow convergence rate and falling into the local best during the process of inversion of atmospheric duct. Taking the inversion of the surface duct using RFC technique as an example, the propagation characteristics of radar sea clutter obtained from the simulated and measured refractivity profile are treated as the observed sea clutter power to examine the performance of OGABC, respectively. For the simulated refractivity profile case, the Gaussian noise is added to the simulated radar sea clutter power to investigate the stability of the proposed OGABC algorithm, and the histograms and the convergence curves are used to analyze the accuracy and convergence rate. Further investigation using the radar sea clutter power generated by the measured refractivity profile is also involved, and the accuracy and convergence rate of the algorithms are discussed by comparing the inverted refractivity profile with the measured one and analyzing their convergence 

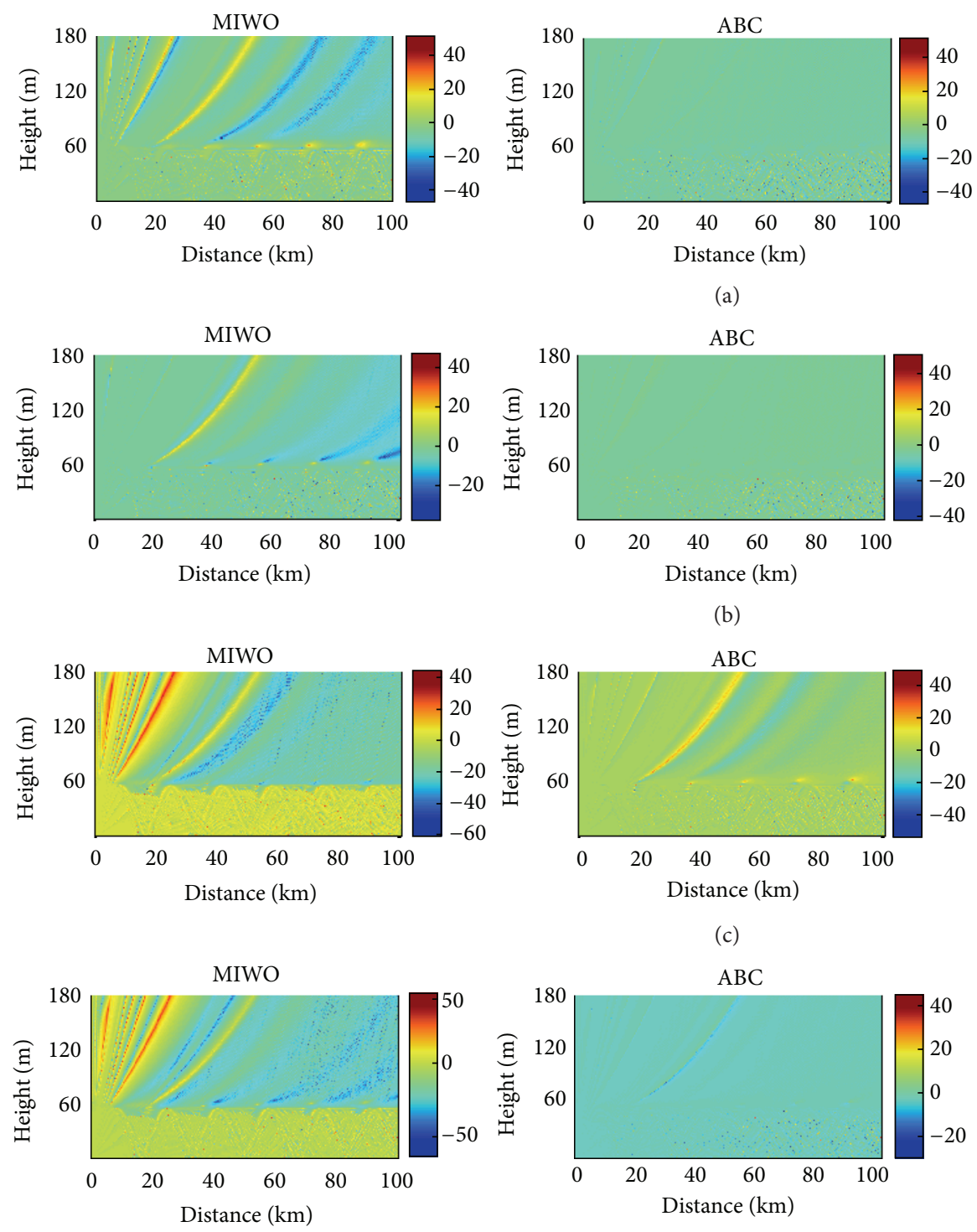

(d)

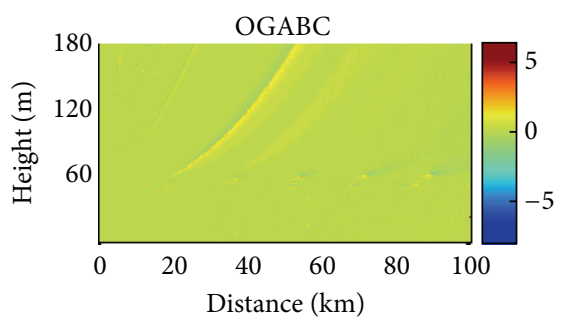

(a)

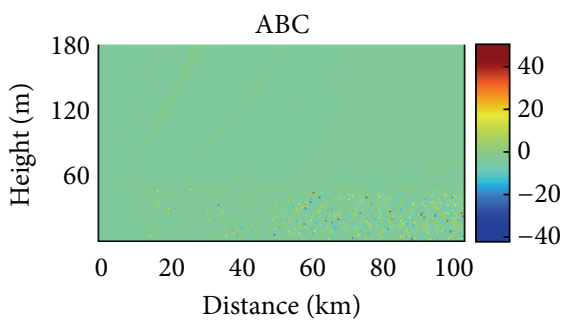

(b)
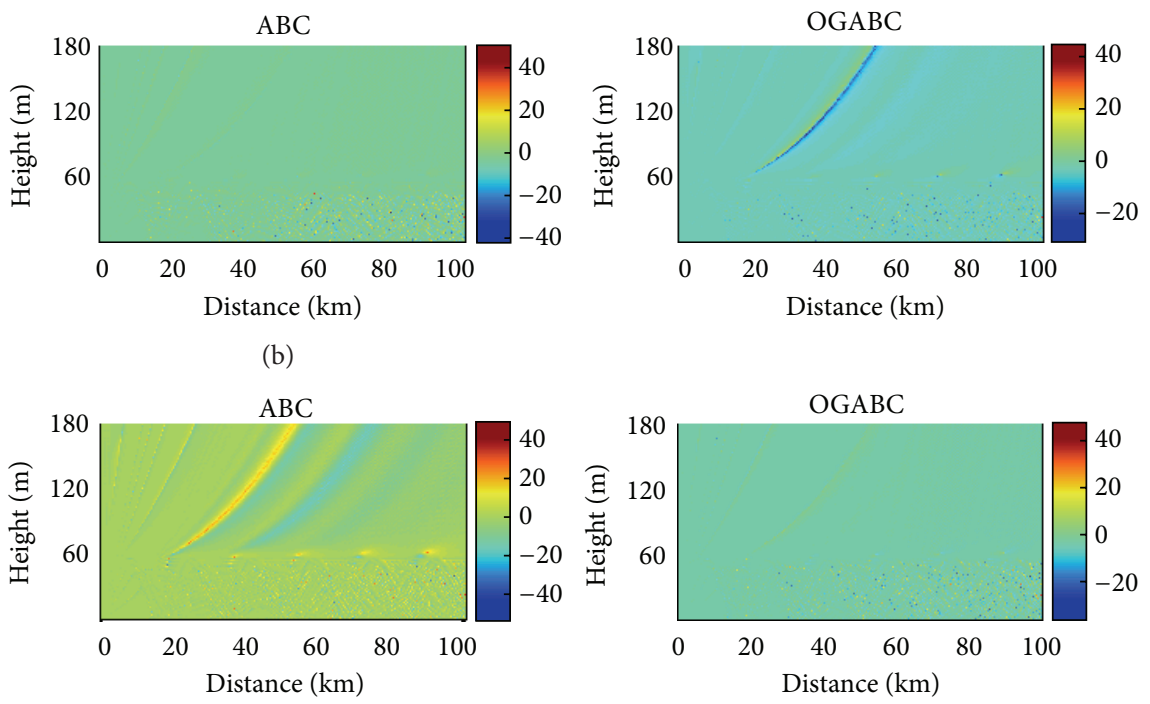

OGABC

OGABC

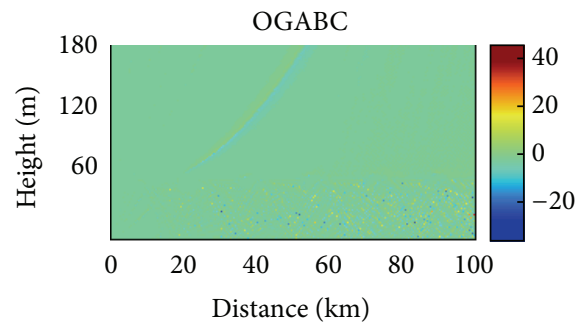

Distance $(\mathrm{km})$

Figure 7: The comparison of the difference between the inverted and actual coverage diagram with different noise level: (a) $0 \mathrm{~dB}$; (b) $1 \mathrm{~dB}$; (c) $2 \mathrm{~dB}$; and (d) $3 \mathrm{~dB}$.

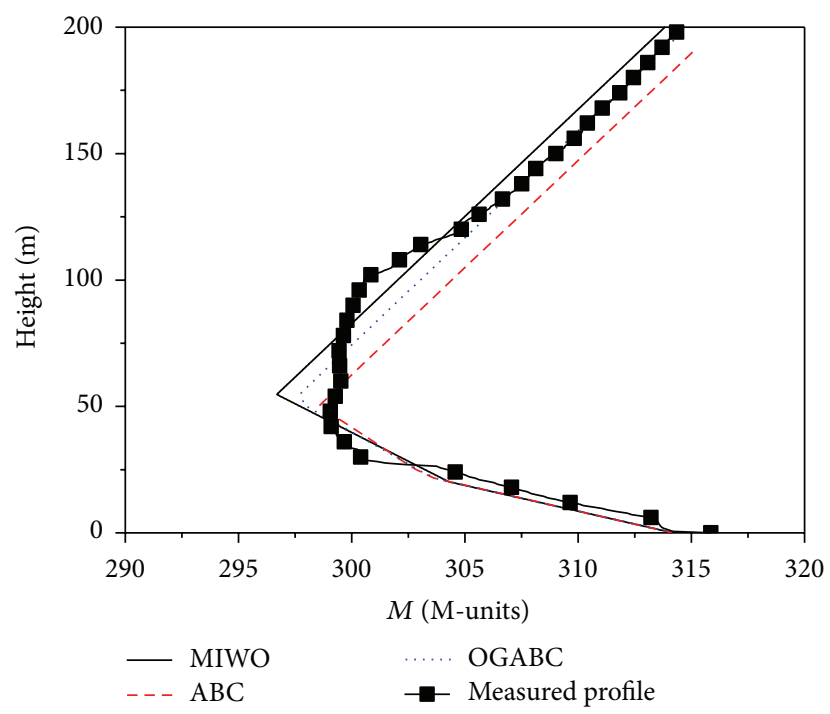

FIGURE 8: The comparison of the inverted profile with the measured profile. 


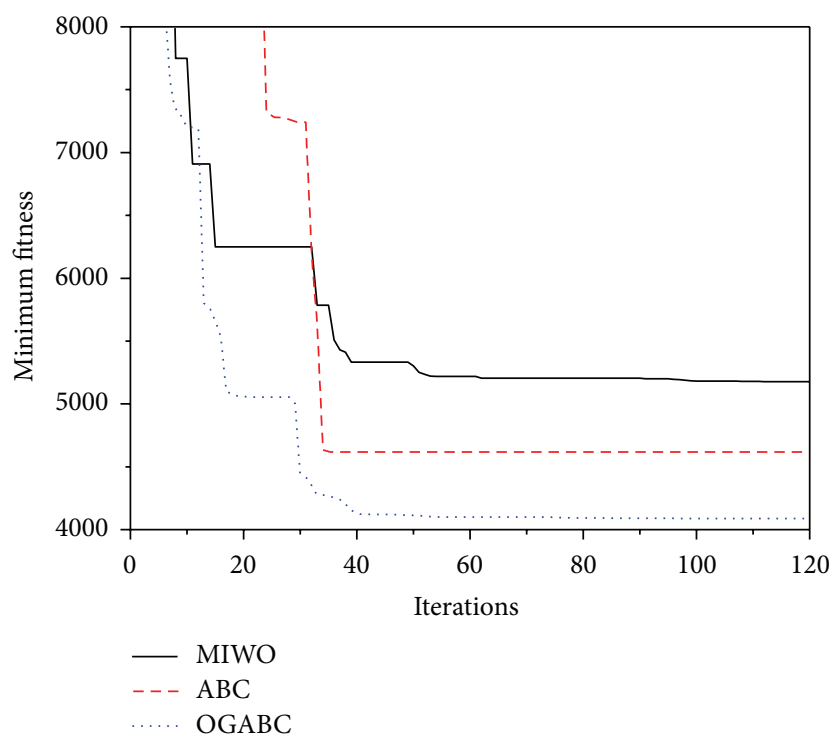

FIGURE 9: The comparison of the convergence curves of different algorithms.

curves. In addition, the inversion results are also analyzed and compared with those of the MIWO and ABC. The obtained results verify that the proposed OGABC algorithm outperforms MIWO and $\mathrm{ABC}$ in terms of stability, accuracy, and convergence rate. Future work will focus on the experimental research and the improvement of the inversion model.

\section{Competing Interests}

The authors declare that there is no conflict of interests regarding the publication of this paper.

\section{Acknowledgments}

This work is supported by the National Science Fund for Distinguished Young Scholars of China (no. 61225002) and the Young Scientists Fund of the National Natural Science Foundation of China (no. 61302050).

\section{References}

[1] C. Yardim, P. Gerstoft, and W. S. Hodgkiss, "Estimation of radio refractivity from radar clutter using Bayesian Monte Carlo analysis," IEEE Transactions on Antennas and Propagation, vol. 54, no. 4, pp. 1318-1327, 2006.

[2] C. Yardim, P. Gerstoft, and W. S. Hodgkiss, "Tracking refractivity from clutter using Kalman and particle filters," IEEE Transactions on Antennas and Propagation, vol. 56, no. 4, pp. 10581070, 2008.

[3] C. Yardim, P. Gerstoft, and W. S. Hodgkiss, "Sensitivity analysis and performance estimation of refractivity from clutter techniques," Radio Science, vol. 44, pp. 1-16, 2009.

[4] P. Gerstoft, L. T. Rogers, J. L. Krolik, and W. S. Hodgkiss, "Inversion for refractivity parameters from radar sea clutter," Radio Science, vol. 38, pp. 1-22, 2003.
[5] A. Karimian, C. Yardim, P. Gerstoft, W. S. Hodgkiss, and A. E. Barrios, "Refractivity estimation from sea clutter: an invited review," Radio Science, vol. 46, pp. 1-16, 2009.

[6] X.-F. Zhao, S.-X. Huang, and H.-D. Du, “Theoretical analysis and numerical experiments of variational adjoint approach for refractivity estimation," Radio Science, vol. 46, no. 1, pp. 1-12, 2011.

[7] X. F. Zhao and S. X. Huang, "Atmospheric duct estimation using radar sea clutter returns by the adjoint method with regularization technique," Journal of Atmospheric and Oceanic Technology, vol. 31, no. 6, pp. 1250-1262, 2014.

[8] R. Douvenot, V. Fabbro, P. Gerstoft, C. Bourlier, and J. Saillard, "A duct mapping method using least squares support vector machines," Radio Science, vol. 43, pp. 1-12, 2008.

[9] B. Wang, Z.-S. Wu, Z.-W. Zhao, and H.-G. Wang, "Retrieving evaporation duct heights from radar sea clutter using particle swarm optimization (PSO) algorithm," Progress In Electromagnetics Research $M$, vol. 9, pp. 79-91, 2009.

[10] X.-F. Zhao, S.-X. Huang, J. Xiang, and W.-L. Shi, "Remote sensing of atmospheric duct parameters using simulated annealing," Chinese Physics B, vol. 20, no. 9, Article ID 099201, 8 pages, 2011.

[11] C. Yang, "Estimation of the atmospheric duct from radar sea clutter using artificial bee colony optimization algorithm," Progress in Electromagnetics Research, vol. 135, pp. 183-199, 2013.

[12] D. Karaboga and B. Basturk, "A powerful and efficient algorithm for numerical function optimization: artificial bee colony (ABC) algorithm," Journal of Global Optimization, vol. 39, no. 3, pp. 459-471, 2007.

[13] J. Yang, W.-T. Li, X.-W. Shi, L. Xin, and J.-F. Yu, "A hybrid ABC$\mathrm{DE}$ algorithm and its application for time-modulated arrays pattern synthesis," IEEE Transactions on Antennas and Propagation, vol. 61, no. 11, pp. 5485-5495, 2013.

[14] X. Zhang, X. Zhang, S. Y. Yuen, S. L. Ho, and W. N. Fu, "An improved artificial bee colony algorithm for optimal design of electromagnetic devices," IEEE Transactions on Magnetics, vol. 49, no. 8, pp. 4811-4816, 2013.

[15] S. K. Goudos, K. Siakavara, A. Theopoulos, E. E. Vafiadis, and J. N. Sahalos, "Application of Gbest-guided artificial beecolony algorithm to passive UHF RFID tag design," International Journal of Microwave and Wireless Technologies, 2015.

[16] G. Zhu and S. Kwong, "Gbest-guided artificial bee colony algorithm for numerical function optimization," Applied Mathematics and Computation, vol. 217, no. 7, pp. 3166-3173, 2010.

[17] W.-F. Gao, S.-Y. Liu, and L.-L. Huang, "A novel artificial bee colony algorithm based on modified search equation and orthogonal learning," IEEE Transactions on Cybernetics, vol. 43, no. 3, pp. 1011-1024, 2013.

[18] R. S. Rahnamayan, H. R. Tizhoosh, and M. M. A. Salama, "Opposition-based differential evolution," IEEE Transactions on Evolutionary Computation, vol. 12, no. 1, pp. 64-79, 2008.

[19] A. E. Barrios, "Terrain parabolic equation model for propagation in the troposphere," IEEE Transactions on Antennas and Propagation, vol. 42, no. 1, pp. 90-98, 1994.

[20] A. Karimian, C. Yardim, W. S. Hodgkiss, P. Gerstoft, and A. E. Barrios, "Estimation of radio refractivity using a multiple angle clutter model," Radio Science, vol. 47, pp. 1-9, 2012.

[21] A. Basak, D. Maity, and S. Das, "A differential invasive weed optimization algorithm for improved global numerical optimization," Applied Mathematics and Computation, vol. 219, no. 12, pp. 6645-6668, 2013. 


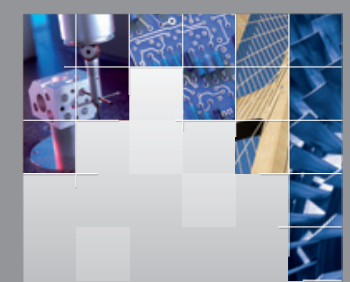

\section{Enfincering}
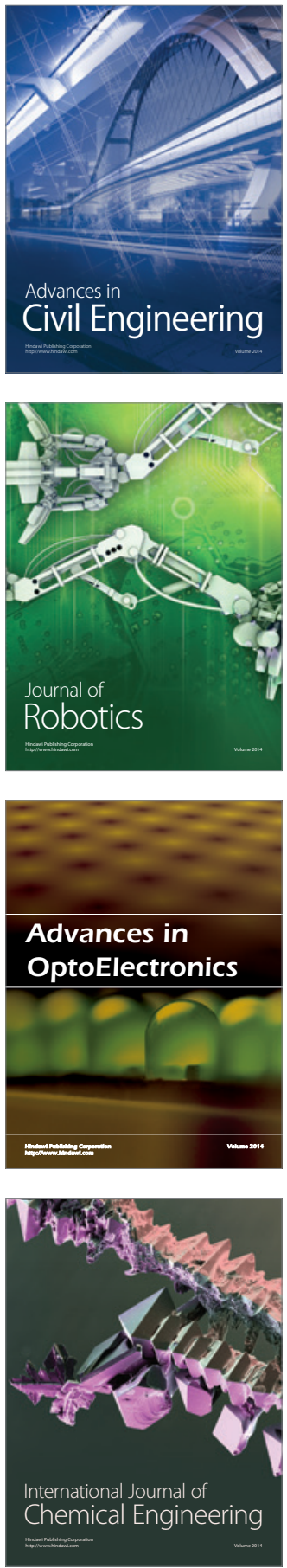

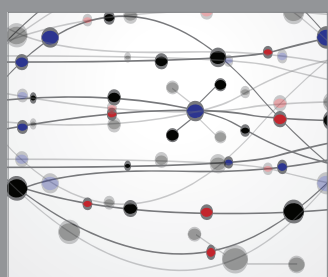

The Scientific World Journal

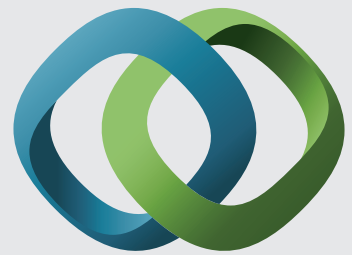

\section{Hindawi}

Submit your manuscripts at

http://www.hindawi.com
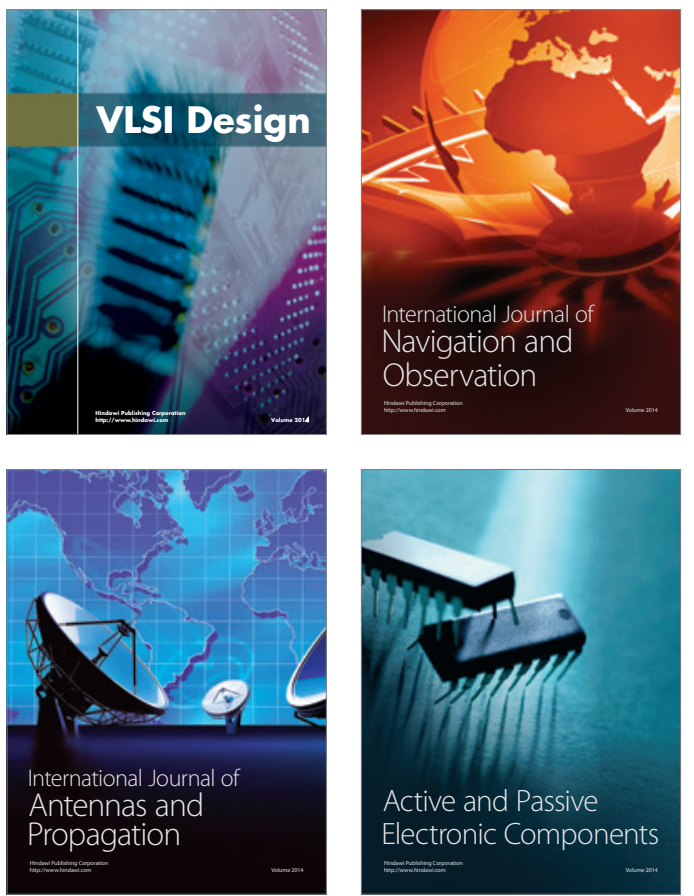
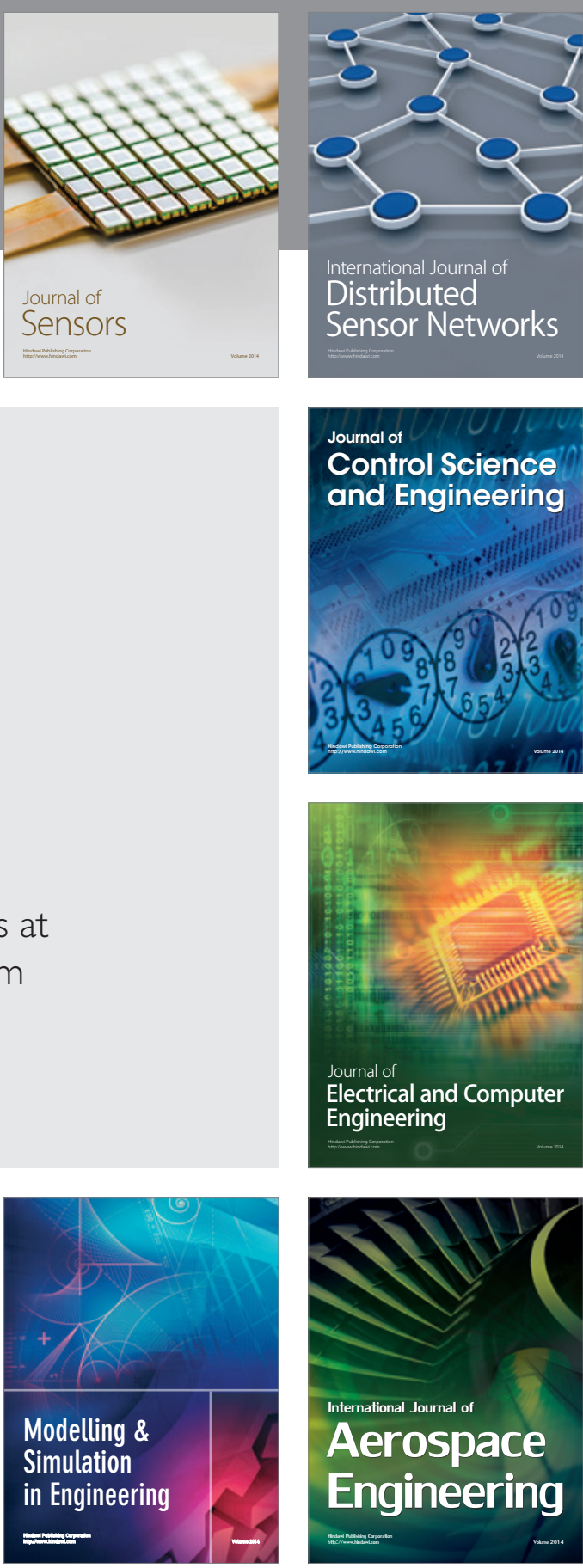

International Journal of

Distributed

Sensor Networks

Journal of

Control Science

and Engineering
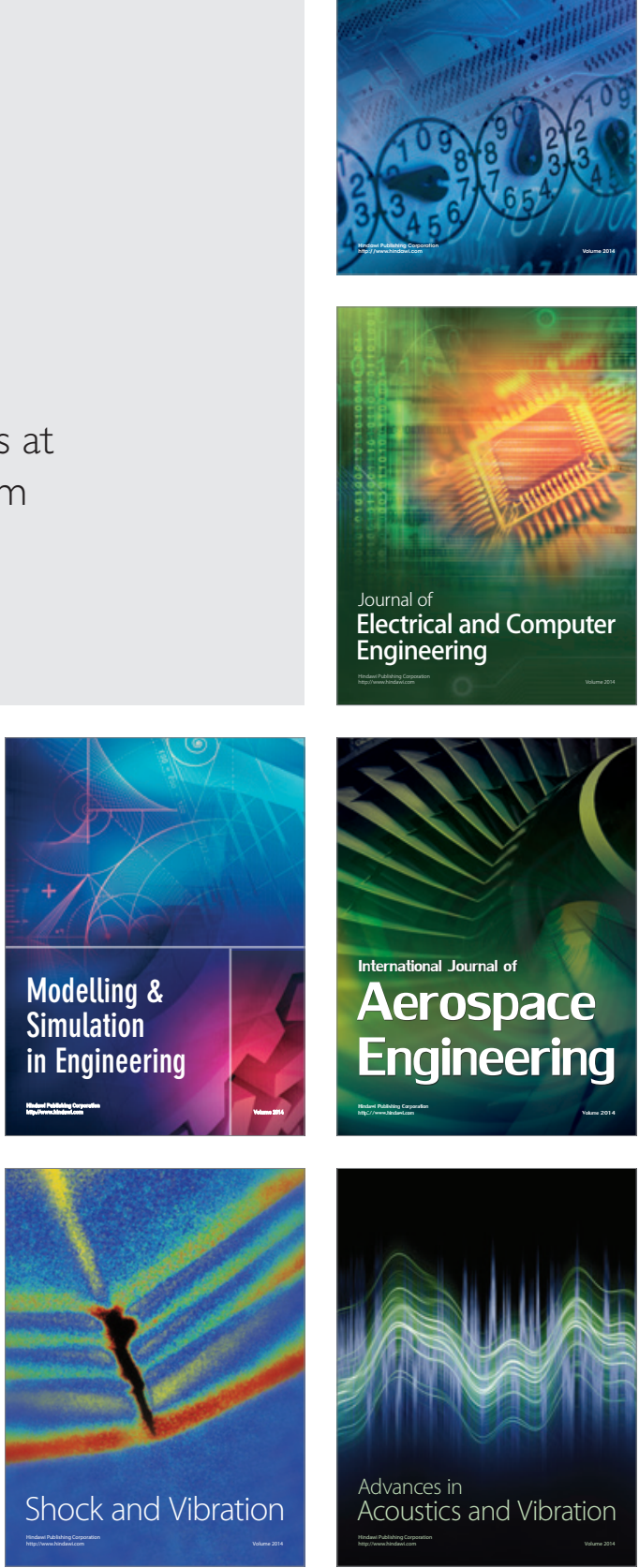